\title{
Research on the Design of Legal Basic Teaching System Based on Computer Network
}

\author{
Xiao Han
}

Wuhan Engineering Institute, Wuhan, Hubei, 430403

Keywords: legal education; education information; computer network

\begin{abstract}
Informatization of law education is an important part of educational informatization, which plays a vital role in promoting the development of legal education. On the basis of fully summarizing and inheriting predecessors' research results and advanced experience, combining the characteristics and requirements of legal education, this paper focuses on the exploration and establishment of the legal foundation education platform under the modern information management system, to provide a good platform for information query and sharing in law education.
\end{abstract}

\section{Introduction}

In recent years, the knowledge economy is beginning to emerge, the wave of information has spread to every corner of the world. In today's wave of information society, driven by information technology, the development of educational informatization aimed at training the talents needed in the information society is in full swing. To improve the use level of educational resources by means of information technology, optimize the operating efficiency of educational institutions, and explore new teaching mode. Educational informatization has become an important part of the reform and development of higher education in the world.

Informationalization of law basis education is an important part of educational informatization, which plays a vital role in promoting the development of legal education. The informationization of legal education is mainly reflected in the application of computer network technology in law education. Therefore, this paper puts forward to construct a law basis teaching system based on computer network, and establish its content system.

\section{Planning of Legal Basic Teaching System}

We are currently facing one unavoidable problem that is how to make full use of the existing databases to achieve effective integration, management, application and appreciation of legal education resources, how to make use of a technology platform to realize the explicit knowledge of individual tacit knowledge, how to transform these extremely valuable individual tacit knowledge into explicit knowledge resources of all legal persons through sharing and exchanging, so as to achieve continuous improvement of individual quality and organizational wisdom. China's current realistic background urgently needs a timely update, convenient and fast legal basic teaching system, with large amount of information, which integrates existing legal education information resources, to finally serve all legal learners.

Therefore, in this paper, the design of law basis teaching system is proposed, and its design objective, system positioning and target audience of the system is successively elaborated.

\subsection{System objective.}

Through the software and hardware construction of the database system, the goal of the law basis education system is to build a hub for the development, utilization, distribution, exchange, sharing and management of Chinese legal education information resources. 


\subsubsection{Overall objective.}

The overall objective of the law basis education system is as follow:

a) Realize the construction of the basic knowledge base of law and resource management;

b) Realize real-time information release, query and other functions;

c) Construct a platform for free interaction and communication between users;

d) Achieve multi-level user registration and certification system.

\subsubsection{Technical objective.}

The technical objective of the law basis education system is as follow:

a) Easy to add, modify, delete and maintain;

b) Ensure database security, by taking the necessary encryption and security measures, so that effectively prevent external loss of the database;

c) To fully reflect the convenience, applicability and openness of the database system, as well as meeting the evolving needs, the system should have sufficient flexibility to expand;

d) Fully consider existing legal database resources, and should be connected and shared with other database systems as much as possible, such as law and regulation database, CNKI journal database, dissertation database, etc.;

e) It requires detailed testing of various technical performance indicators of the system;

f) Database and WEB design requirements to establish standardized documentation at all levels.

\subsubsection{User interaction objective.}

The user interaction objective of the law basis education system is as follow:

a) In structural design, the page should be designed with an open structure, with larger scalability;

b) In the use of pictures, with text and color blocks, express the strength and creativity of the website with vivid image; website is unified the color system as far as possible, while Different columns and sub websites display different hue, In order to show the personalization of different column;

c) For the layout, column centralized display, navigation mark clear and it should be convenient for users to browse;

d) In color application, with the prevailing color of saturation color as the dominant color, warm color as auxiliary color, and the overall color presents a professional, concise, lively, relaxed, fresh and generous feature, and full of modern sense;

e) In detail design, pay attention to smooth lines and full space left blank;

f) Optimize the page to ensure enough download speed.

\subsection{System orientation.}

The orientation of the legal basic education platform is to determine its nature in the entire legal education information, which directly determine the target audience, design principles and structural content of the law basis education system. We believe that the legal basic education platform should assume as service platform, promotion platform, communication platform, dialogue platform, research platform, teaching platform and intermediary platform.

\subsubsection{Service platform.}

This is the primary position of the legal basis system, that is, to build the system into a shared legal education information resource center, providing inquiry services for legal education information to users, to allow user realize real-time legal information inquiry by means of the network, and complete the transmission of legal education information through the network. Through the establishment of a complete retrieval system, make it a powerful helper for legal research, teaching, and independent learning. The legal basic education service platform embodies the importance of computer-aided law education based on the Internet in the 21st century education. 


\subsubsection{Promotion platform.}

First of all, the law basis education platform will become an important field to promote the country's principles and policies on legal education. Secondly, on the law basis education platform, all legal persons are free to publish their own articles, to participate in various discussions, and to fully display and promote themselves. The legal basic education platform will become the best platform for grassroots law schools, law teaching and research personnel, and students to show their style.

\subsubsection{Communication platform.}

The law basis education platform will become a field of information exchange become educational researchers, students and legal practitioners, as well as the front camp to explore the hot and difficult issues of legal education reform.

\subsubsection{Dialogue platform.}

Through the establishment of bulletin boards, message boards, forums, mailboxes and other means, the law basis education platform collects feedback from all parties, consults the community for advice and contributions to legal education and replies to the user's question. Therefore, the law basis education platform will become a dialogue platform for legal knowledge education.

\subsubsection{Research platform.}

Information is the cornerstone of the academic building. Traditional legal research has always been based on paper media and newspapers, while legal documents printed on newspapers or books will never change. It also has the disadvantages of long production cycle, slow propagation speed and narrow audience swipe. In short, such method and means of legal research is backward. The emergence of network technology has revolutionized the methods of legal research. The law basis education platform will extend legal research to the network, to become a comprehensive research platform for Chinese law.

\subsubsection{Teaching platform.}

In the traditional sense, legal teaching must be carried out at a certain time and at a specific location, but this way is quite restrictive. This limitation is manifested in: on the one hand, Teachers are often busy, uniform fixed time and place may cost quite a lot; on the other hand, many discussions are often unable to go deeper in a limited time frame. The law basis education platform can provide a platform for law teachers and students to break the time and space constraints through the network media, and allow teachers and students to learn, communicate, and discuss online, anytime, anywhere.

For legal basic teaching, discussion is the most important form and approach. Online teaching can record the discussion process, save the spark of thought in the discussion.

The Educational function of law basis education platform would also enable each group of students to learn about the content of the class discussion of their seniors. Based on this, proceed further discussion in depth and breadth year after year and thus the depth of research continues to expand.

\subsubsection{Intermediary platform.}

The law basis education platform should develop into an important branch of the national education information resource center, and establish a law website information resource network and other related websites similar to national education information network center website, to realize the integration of information resources in cyberspace and act as an intermediary for various resource services.

\subsection{Target audience.}

The target audience of law basis education platform is the basic problem that must be clarified in 
the construction of the law basis education platform. Determined by the positioning of the law basis education platform, we think that this system covers two types of target audiences as follow:

\subsubsection{Institutional audience.}

Institutional audience of the law basis education platform includes:

a) Legal colleges and Universities;

b) Legal scientific research institutions;

c) Legislation, law enforcement, and judicial institutions;

d) Law firm;

e) Legal related enterprises.

\subsubsection{Individual audience.}

Individual audience of the law basis education platform includes:

a) Science and research personnel of law education, including law teachers and scholars;

b) Student of law majors;

c) Judicial personnel, including judges, prosecutors, police officers, administrative law enforcers, discipline inspection and supervision personnel, etc.;

d) Legal practitioner, including lawyers, legal media practitioners, etc.;

e) Law lovers.

\section{Overall Design of Legal Basic Teaching System}

\subsection{Overall framework.}

The law basis education platform designed in this paper includes three main subsystems: personal knowledge management subsystem, cooperative learning subsystem and knowledge base subsystem.

The overall framework of knowledge management platform is shown in Fig.1.

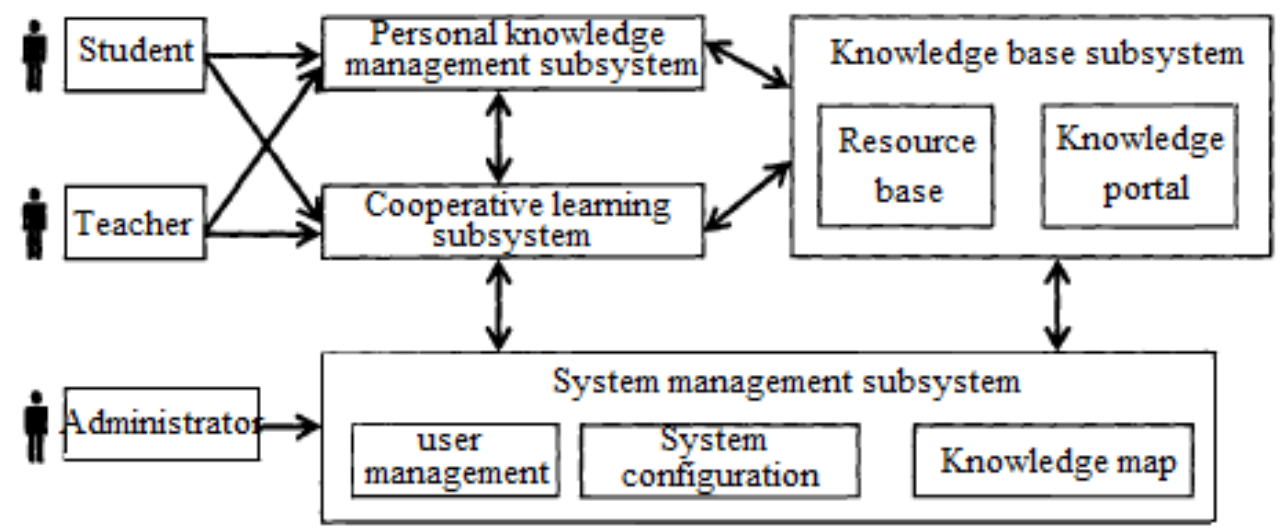

Fig. 1. Overall framework of law basis education platform

The law basis education platform sets three roles: student, teacher and administrator, which are described as follow:

a) Student: students use knowledge management platform for personal knowledge management, and implement autonomous learning; interact with other users of the system, promoting informal learning. In addition, students can also participate in the project-based learning group, to accomplish the construction and sharing of legal knowledge through collective cooperation.

b) Teacher: teachers will help students acquire knowledge and promote knowledge sharing, by creating and guiding project-based online collaboration. Similarly, teachers can also use the platform for personal knowledge management, and thus promote the growth of their own individual knowledge. 
c) Administrator: administrator is responsible for audit management of system user registration and project team leader application. Certainly, administrator has permission to set the system configuration and parameters.

\subsection{Logical architecture.}

In the construction and operation process of law basis education platform, the relationship between construction and application at all levels is complementary. For the whole system, it can be divided into parts of System support platform, business system, application middleware, portal website, security system and management system, as shown in Fig.2.
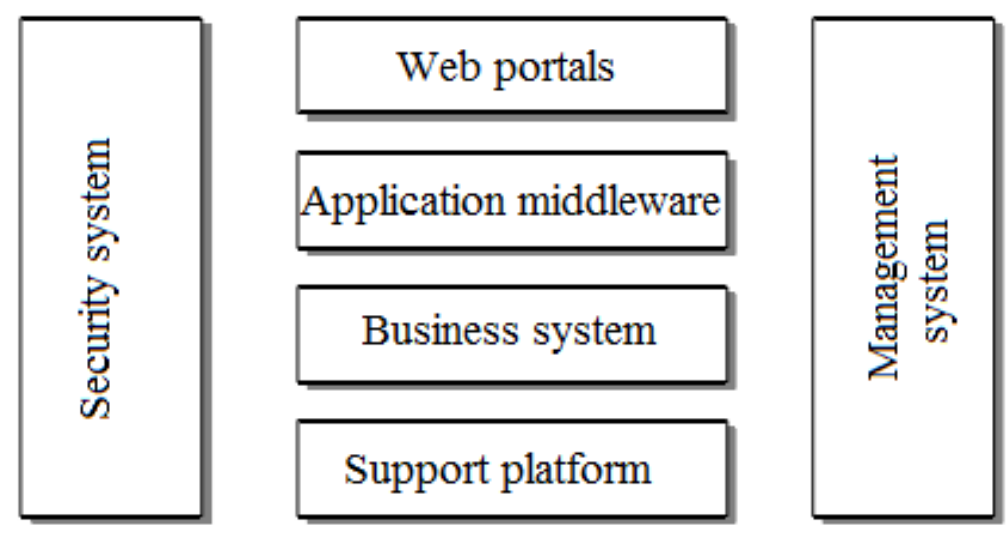

Fig.2. Logical architecture of law basis education platform

\subsubsection{System support platform.}

The system support platform mainly includes network equipment, host, storage and other hardware systems. It provides a hardware support environment for system construction, and it belongs to the subordinate position in the design. Its specific configuration depends on the system's requirements for reliability, performance and security, and meanwhile should take full account of the extensibility of the system.

\subsubsection{Business system.}

The business system includes a database system, a business processing system, and so on. The data system is the heart of the whole system, so in the construction of the system, system security and data security should be considered.

\subsubsection{Application middleware.}

The application middleware mainly refers to WEB application servers. The application server is a container for all applications of the web site, and various applications will run in the application server, so the robustness of the system and the support for application types are very important.

\subsubsection{Portal site.}

Portal site includes functional applications, management applications and application gateways. The application part of the system will complete the business needs of the system. The application gateway mainly completes the information publishing, management, forums, traffic analysis and so on.

\subsubsection{Management system.}

Management system is an important part of the system to ensure the operation of the system. Different management systems are applied corresponding to different levels. It covers the management system of support platform, database, application server and business application. In the design of management system, system integrity and interactivity should be considered. 


\subsubsection{Security system.}

The security system design of the network is also divided into different levels, to provide different levels of protection for networks, hosts, databases, and applications.

\section{Realization of Legal Basic Teaching System}

The basic structure of law basis education platform refers to what the database should contain, and how content is structured. Specifically, the system implementation process can be described from three parts: content system, column setting and module analysis.

Content system. The content system of law basis education platform refers to the question of what data, information, and content the system should contain. The structure of the content system directly affects the success or failure of the law basis education platform.

The law basis education platform should contain the three parts of subject, activity and object, as shown in Fig.3.

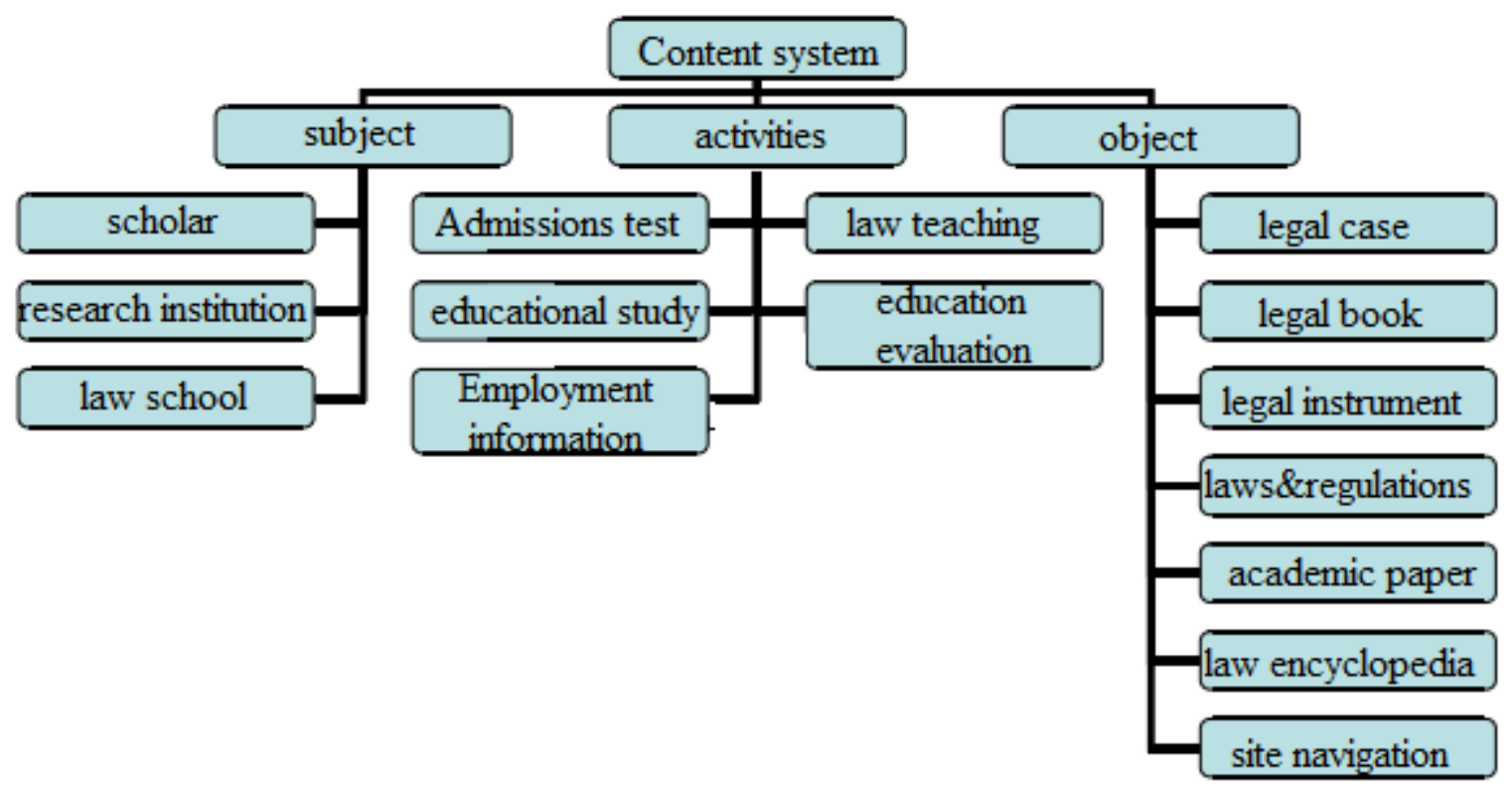

Fig.3. The content system of law basis education platform

News and information. It includes the latest news of law education, as well as national policy and the rule of law.

Legal education research. Should include domestic policies and regulations on legal education, the latest research results, etc.

Legal education evaluation. Includes policy and regulations, theoretical research, specific design plans, assessment reports, and training information for evaluation experts in the evaluation of education in law subjects.

Admissions test. Various admissions examination information related to legal education, such as master of laws examination, self-taught examination, judicial examination, etc.

Employment information. A collection of relevant information about the employment of law students.

Judicial case. Various judicial cases at home and abroad, typical cases, rulings and case judgments are included.

Information of law schools and research institutions. Include the introduction, history, enrollment information, Faculty strength and scientific research level of law schools.

Classified subject information. Divide the contents of the whole database of legal education into the users according to the classification of law.

Laws and regulations. A variety of domestic and foreign laws and regulations are included. 
Legal instrument. The judicial administrative organs and parties, lawyers are included in the settlement of litigation and non-litigation cases, including non-normative documents of the judicial organs.

\section{Conclusion}

On the basis of fully summarizing and inheriting predecessors' research results and advanced experience, combining the characteristics and requirements of legal education, this article focuses on the exploration and establishment of the legal foundation education platform under the modern information management system, to provide a good platform for information query and sharing in law education.

\section{Acknowledgements}

This paper is grateful for the support of provincial level teaching research item of institution of higher learning in Hubei province (No.2017572): Research on teaching political theory course of higher vocational college under the background of new media.

\section{References}

[1] He S. Research and Implementation of Student Entrepreneurship Legal Education Training Network Platform[J]. Office Informatization, 2011.

[2] Brand R A. Building on the Bergsten Legacy: The Vis Moot as a Platform for Legal Education[J]. 2015, 34(1).

[3] Lachmayer K. Teaching Constitutional Comparison. Changing the Culture of Legal Education[M]// International Constitutional Law in Legal Education. 2014:2995-3007.

[4] Xuan G, Cheng H. A Controllable Law Practice Teaching System in Local Applied Universities[J]. Journal of Ningbo University, 2016.

[5] Jiang J. Law Practice Teaching Research System[J]. Journal of Ankang University, 2009.

[6] Wen J. An Empirical Study of the Assessment System of Criminal Law Case Teaching[J]. Journal of Railway Police College, 2010.

[7] Kang L N. Construction of International Law Network Teaching Platform in Universities[J]. Journal of Heilongjiang Administrative Cadre College of Politics \& Law, 2014, 23(4):452-477. 